\title{
Comparative Study on Building Energy Consumption Requirements of Retail Buildings
}

\author{
Gu Zhongxuan, Zhong Min, Liu Lili, Sheng Xiyou, Luo Shuxiang, Wu Yanli
}

Beijing Building Technology Development CO., LTD., Beijing, China

\section{Email address:}

guzhongxuan@bbtdc.com (Gu Zhongxuan), zhongmin@bbtdc.com (Zhong Min), Liulili@bbtdc.com (Liu Lili), shengxiyou@bbtdc.com (Sheng Xiyou), luoshuxiang@bbtdc.com (Luo Shuxiang),wuyangli@bbtdc.com (Wu Yanli)

\section{To cite this article:}

Gu Zhongxuan, Zhong Min, Liu Lili, Sheng Xiyou, Luo Shuxiang, Wu Yanli. Comparative Study on Building Energy Consumption Requirements of Retail Buildings. American Journal of Civil Engineering. Vol. 4, No. 6, 2016, pp. 372-375. doi: 10.11648/j.ajce.20160406.25

Received: November 10, 2016; Accepted: December 7, 2016; Published: December 9, 2016

\begin{abstract}
As one of the biggest parts of total building energy consumption, public buildings energy efficiency catch the eyes of policy makers and researchers. Recently, both national and local energy consumption requirements for public buildings are being developed. In this article, we compared the energy consumption requirements for a major type of public building (retail building) and analyzed the differences and similarities of the requirements. In the end, suggestions for developing building energy consumption requirements are given based on our comparative study.
\end{abstract}

Keywords: Building Energy Consumption, Standard, Retail Buildings

\section{Introduction}

Existing non-energy efficient public buildings in Beijing total 170 million square meters in area and these buildings are energy intensive and therefore have a huge energy saving potential [1].

In order to help reduce the energy use intensity (EUI) of existing public buildings, policies and recommendation standards regarding building energy consumption are being stipulated in recent years. Most-recent examples of such standards are Standard for Energy Consumption of Civil Buildings (GB/T 51161-2016) [2] at national level and The Stipulation of Energy Consumption of the Department Store and Supermarket (DB11/T 1159-2015 )[3], The Stipulation of Energy Consumption of Universities and Colleges (DB11/T 1267-2015) [4], The Stipulation of Energy Consumption of Culture Venues (DB11/T 1268-2015) [5], and The Stipulation of Energy Consumption of Stadiums (DB11/T 1296-2015) [6] at local level.

In addition to standards, the Beijing municipal government also created policy [7]. to direct control the energy consumption of public buildings with area bigger than 3000 square meters.

Of all types of public building, the energy intensity of retail buildings is the highest [8,9], therefore this paper focuses on the energy consumption of retail buildings. The development of retail building energy consumption requirements are usually based on statistical studies of building history energy consumption [10]. We made a comparative study of the policy and standards, and discovered that for retail buildings (department stores, supermarkets and shops) the energy consumption requirements in standards and policy are often different. Therefore a detailed analysis of the differences is necessary to the implementation of standards and policy.

\section{Summary of Standards and Policy}

\subsection{National Standard}

Standard for Energy Consumption of Civil Building is the first national standard which provided EUI indicators for three major types of public buildings (office building, hotel building and retail building). The recommendation EUI values are derived from statistical analysis based on a large set of building energy use data collected during the practice of building energy survey and energy audit of major cities of China. The publication of the standard is a major step in the control of building energy.

Energy consumption indicators are divided into constraint values and leading values, constraint values are the maximum energy consumption allowed for a given building 
type whereas leading values are expected energy consumption for a given building type where comprehensive technical and management measures for building energy efficiency are used.

Considering the difference in how the built environment is maintained, public buildings are divided into Type A (natural ventilation is possible) and Type B (only mechanic cooling and heating is possible).

Retail building is a major type of public building, in the national standard energy consumption requirements for retail building (both Type A and Type B) are given.

\subsection{Local Standard}

Local building energy standard is an important component in Beijing municipal government's regulation of building energy consumption. For the retail building sector, the local standard The Stipulation of Energy Consumption of the Department Store and Supermarket gave energy consumption requirements for major type of retail buildings such as department stores and supermarkets.

\subsection{Local Policy}

The national and local standard introduced above are all voluntary standards, in additional to these voluntary standards, Beijing municipal government also announced local policy aimed at direct control of the public building electric consumption.

Under the current policy, all public buildings with an area more than $3,000 \mathrm{~m}^{2}$ are listed in a government database and their yearly electric consumption is capped. The current policy requires their electric consumption be reduced by $6 \%$ compared with the base year consumption of 2011 .

\section{Requirements for Energy Consumption of Retail Buildings}

Standards and policy use different methodology to control the building energy consumption. In the national and local standard, Energy Consumption Indicators are given for each type of building, prescribing how much energy can be consumed per square meter of building area. However in the local policy, no such indicator is given, the total electric consumption is simply required to reduce a certain amount based on the buildings historic consumption in a base-year. We will discuss the two method in detail below.

\subsection{Methodologies}

\subsubsection{Energy Consumption Indicators}

Energy consumption indicators are developed to indicate the energy consumption level and energy use intensity of different buildings. Considering the variety in operational \& physical characteristics of buildings, a classification system is needed so that buildings with similar characteristics can be benchmarked using the same indicators.

The national standard combines two major systems for classifying buildings: (a) the system based on how the built environment is maintained and (b) the system based on commercial activities of the building.

The following is the classification of retail buildings in the national standard:

Table 1. Classification of retail buildings in the national standard.

\begin{tabular}{ll}
\hline Retail building sub-type & \\
\hline & Department store \\
Type A (Natural & Shopping center \\
Ventilation) & Supermarket \\
& Restaurant \\
& Shop \\
Type B (Mechanical & Large scale department store \\
Cooling and Heating) & Large scale shopping center \\
& Large scale supermarket \\
\hline
\end{tabular}

The local standard classification system only considers the commercial activities of the building, and the following is the classification of retail buildings in the local standard:

Table 2. Classification of retail buildings in the local standard.

Retail building sub-type

Department store

Supermarket

Specialty store

For each sub-type of retail building, a set of energy consumption indicators are given. In the national standard, energy consumption indicators include constraint values and leading values; and in the local standard energy consumption indicators are limit values, access values, and advanced values.

Table 3. Energy consumption indicators in national and local standard.

\begin{tabular}{|c|c|c|}
\hline $\begin{array}{l}\text { National } \\
\text { Standard }\end{array}$ & $\begin{array}{l}\text { Local } \\
\text { Standard }\end{array}$ & Description \\
\hline $\begin{array}{l}\text { Constraint } \\
\text { value }\end{array}$ & Limit Value & $\begin{array}{l}\text { The maximum allowed energy } \\
\text { consumption for a building }\end{array}$ \\
\hline $\begin{array}{l}\text { Leading } \\
\text { value }\end{array}$ & Advanced Value & $\begin{array}{l}\text { The expected energy consumption for } \\
\text { a building with comprehensive } \\
\text { technical and management building } \\
\text { energy efficiency measures }\end{array}$ \\
\hline ----- & Access Value & Only applies for new constructions \\
\hline
\end{tabular}

\subsubsection{The Base-Year Method}

The local policy adopts a different methodology, instead of using energy consumption indicators, the base-year method is used, which requires the annual electric consumption of any qualified building be reduced by $6 \%$ each year compared with the consumption of base-year 2011.

Since the reduction is made compared with the building's history consumption, each building has its unique energy reduction target. Therefore, the local policy do not need a classification system of buildings.

\subsection{Comparison of Different Requirements}

National standard, local standard and local policy gave energy consumption requirements from different aspects. In the national and local standard energy consumption 
requirements are given in the form of energy consumption indicators which prescribe how much energy consumption is allowed per unit building area. Energy consumption indicators are given for different sub-types of retail buildings. The local policy use the base-year method to determine how much energy a building can use annually, which requires the history electric consumption of the building to calculate the electric consumption allowed to use.

The methods used in standard and policy both have their pros and cons. The advantage of energy consumption indicators is that they made benchmarking possible, buildings can compare their energy consumption against buildings of the same sub-type and better understand their energy saving potential. The disadvantage of energy consumption indicators is that the development of indicators depends on the quantity and quality of building energy surveys, at this time the national standard only gives energy consumption indicators for three major building types (office, hotel, and retail building). The benefits of using base-year method is that the energy consumption is only compared with the building's history consumption therefore can be applied to all types of building. But the selection of base-year should be careful, improper selection of base-year may result to requirements difficult to satisfy.

\subsection{A Case Study of 125 Buildings}

In this study, 125 retail building samples are selected, and the electricity consumption per square meter for each building is first calculated and then compared with the requirements given in national standard, local standard and local policy.

\subsubsection{Actual Energy Consumption Compared with National Standard Requirements}

The actual energy consumption of 125 retail building samples were compared with constraint value and leading value of national standard in the following figure. We select the constraint value and the leading value for the large shopping mall as a reference. The results are shown in Figure 1:

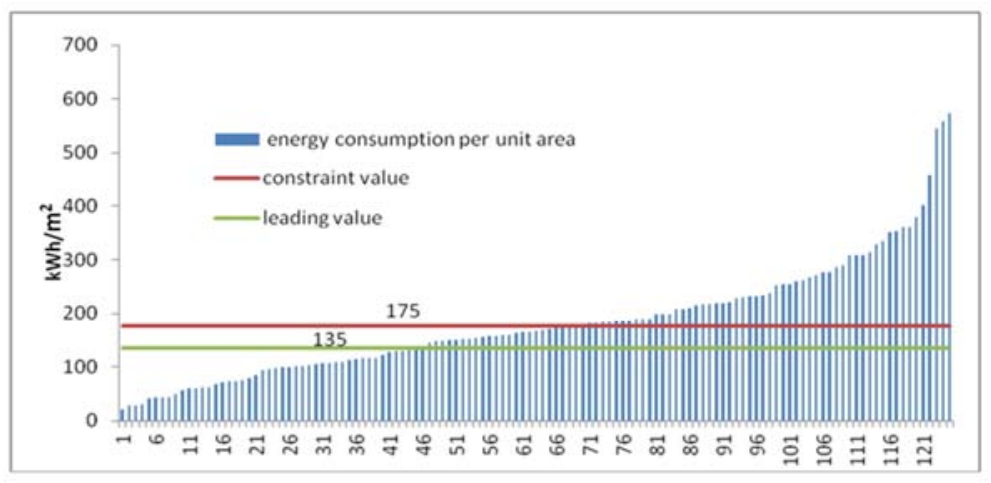

Figure 1. Actual energy consumption compared with the national standard requirements (125 retail buildings).

Vertical coordinate represents actual energy consumption per unit area of 125 retail buildings, the energy use intensity ranges from $20 \mathrm{kWh} / \mathrm{m}^{2}$ to $600 \mathrm{kWh} / \mathrm{m}^{2}$ in Figure 1. The differences in energy use intensity result from several factors: (1) building envelope design, (2) building system design, (3) energy management, (4) building occupancy. Compared with leading value $\left(135 \mathrm{kWh} / \mathrm{m}^{2}\right)$, energy consumption of about $36 \%$ of the buildings are below leading value. Compared with constraint value $\left(175 \mathrm{kWh} / \mathrm{m}^{2}\right)$, energy consumption of about
$53.6 \%$ of the buildings are below constraint value.

\subsubsection{Actual Energy Consumption Compared with Local Standard Requirements}

The actual energy consumption of 125 retail buildings were compared with limit value, access value and advanced value of local standard in the following figure. The results are shown in Figure 2:

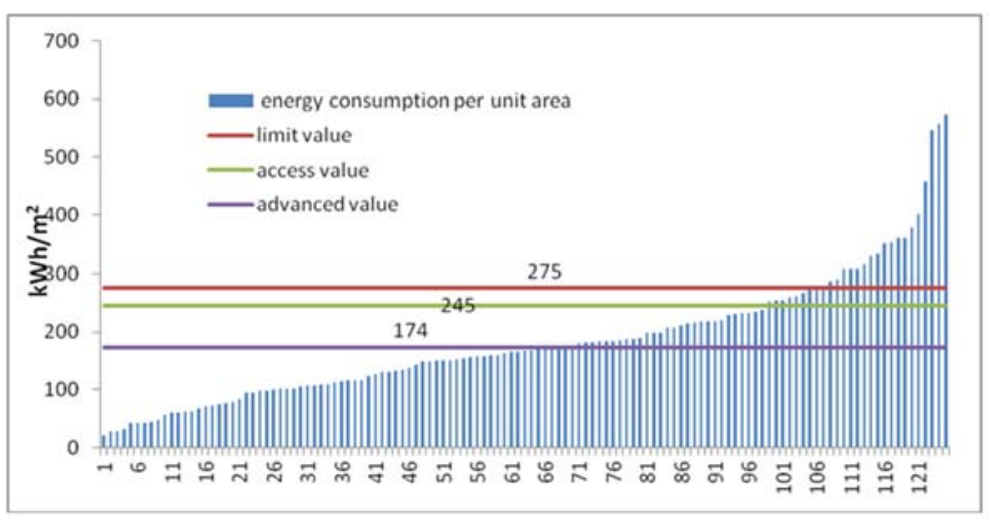

Figure 2. Actual energy consumption compared with the local standard requirements (125 retail buildings). 
Vertical coordinate represents actual energy consumption per unit area of 125 retail buildings. Compared with advanced value $\left(174 \mathrm{kWh} / \mathrm{m}^{2}\right)$, energy consumption of about $53.6 \%$ of the buildings are below advanced value. Compared with access value $\left(245 \mathrm{kWh} / \mathrm{m}^{2}\right)$, energy consumption of about $78.4 \%$ of the buildings are below access value.
Compared with limit value $\left(275 \mathrm{kWh} / \mathrm{m}^{2}\right)$, energy consumption of about $84 \%$ of the buildings are below limit value.

Through the analysis of examples, we find local standard requirements are more loose compared with national standard. The results are shown in Figure 3:

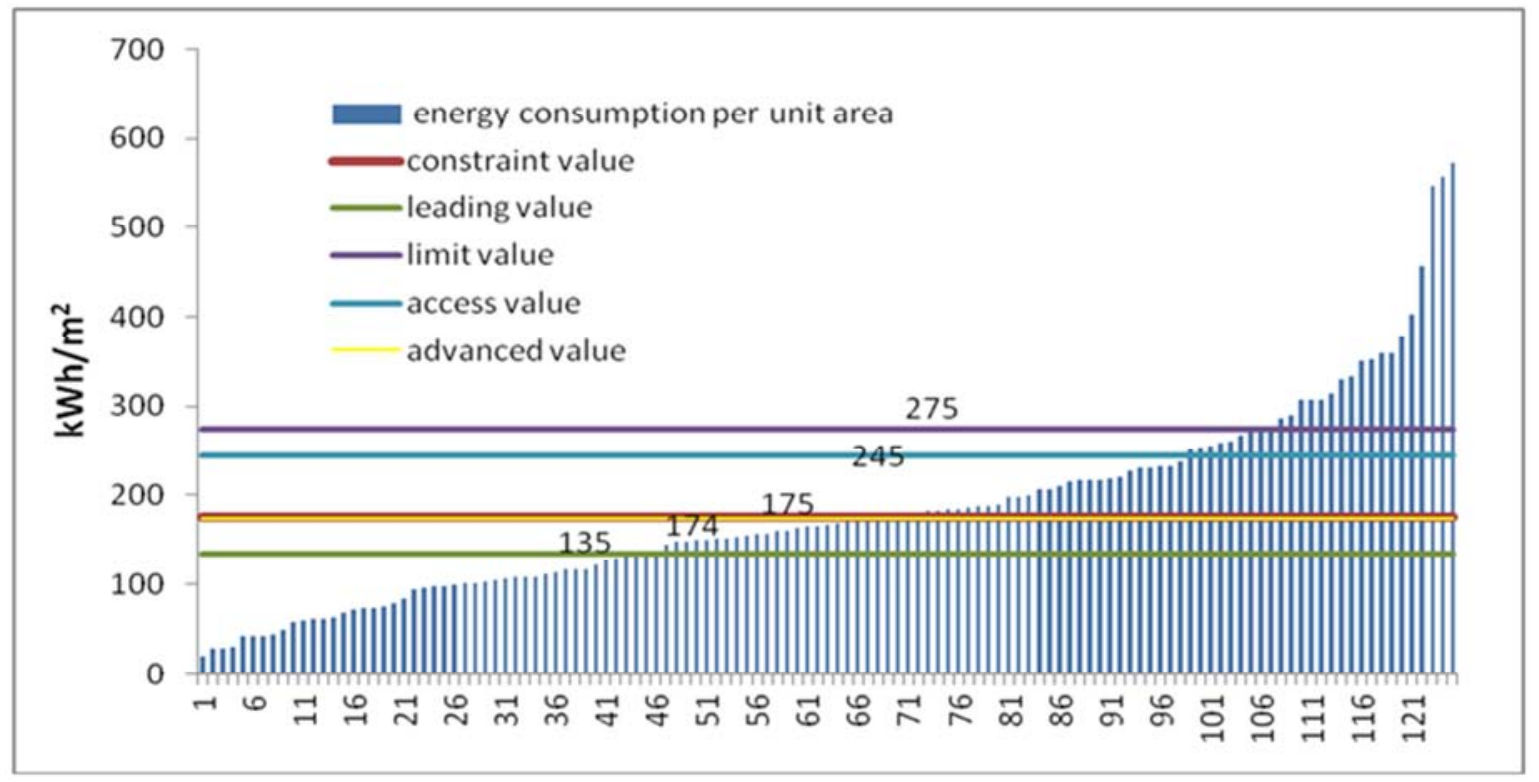

Figure 3. Comparison of two standards and the actual consumption.

It is found that two of the three energy consumption indicators of the national standard are very low in Figure 3. The constraint values are almost overlapped with the advanced values of local standards.

\section{Conclusion}

This paper analyzed the energy consumption requirements in national and local standards, and compared the actual energy consumption of 125 retail buildings with energy consumption requirements in national and local standards. Through the analysis we suggest that when developing energy consumption requirements for retail buildings the following two points should be considered:

(1) The classifications of buildings in national and local standards are different, the national standard divides retail buildings into 5 subtypes, whereas the local standard divides retail buildings into 3 subtypes, the subtypes should be carefully selected before applying the energy consumptions indicators given in the standards.

(2) For a given building subtype, the energy consumption requirements given in the national standard are more difficult to comply with, compared with the requirements in the local standard. This may result from the difference in the selection of sample buildings during the development of the national and local standard or the statistical method they use.

\section{References}

[1] Beijing Public Building Energy Efficiency Promotion Plan (2016-2018).

[2] Standard for Energy Consumption of Building (GB/T 51161-2016).

[3] The Stipulation of Energy Consumption of the Department Store and Supermarket (DB11/T 1159-2015).

[4] The Stipulation of Energy Consumption of Universities and Colleges (DB11/T 1267-2015) (DB11/T 1267-2015).

[5] The Stipulation of Energy Consumption of Culture Venues (DB11/T 1268-2015).

[6] The Stipulation of Energy Consumption of Stadiums (DB11/T 1296-2015)

[7] Provisional Rules on Electricity Consumption Management of Public Buildings in Beijing.

[8] Peng Chen and Jiang Yi, Roadmap for China's Building Energy Conservation, China Building Press, 2015.

[9] Zhan Jiewei, Chen Jianbo, and Zhang Xingyu. Analysis of Building Energy Consumption and Energy Saving Potential of Hypermarket in Shanghai. Building Energy Efficiency, May. 2016.

[10] Sun Duobin, Wang Xin, Xiao He, and Liu Juanjuan. Energy Consumption Quota Research and Demonstration of Large Commercial Buildings. J. of HV\&AC, Sep. 2016. 